\title{
A Escola em Tempo Integral \\ e o Currículo: Em Busca do \\ Inédito e Viável
}

Prof.Dr, Teodoro Adriano Costa Zanardi

\section{RESUMO}

O presente artigo é resultado preliminar de uma pesquisa em curso orientada para a construção de uma proposta curricular, fundada na dialogicidade freireana, para Escola em Tempo Integral. Com a compreensão de que o currículo se traduz no quefazer na escola, tomamos a categoria inédito-viável como a realização do sonho possível, que é a construção coletiva do currículo como fundamento de nossa práxis. A partir da observação e investigação de documentos da escola-parceira e da Secretaria de Estado da Educação de Minas Gerais sobre o projeto curricular das escolas participantes do Projeto Educação em Tempo Integral (PROETI), o grupo envolvido na pesquisa realizou entrevistas e círculos epistemológicos, com o objetivo de construir uma proposta curricular democrática. Sobre bases freireanas, a pesquisa tem caráter qualitativo e como fundamento metodológico a pesquisa-ação, dado que o objetivo é organizar uma intervenção com educadores(as) e educandos(as) no quefazer no tempo integral.

Palavras-chave: Escola em tempo integral. Currículo. Paulo Freire.

\section{ABRSTRACT}

The present article is the preliminary result of an ongoing research, oriented to the construction of a curricular proposal for full-time education that has Paulo Freire's dialogical perspective as foundation. Providing that the curriculum makes for the todos at school, we take the Unknown Viable category as the fulfillment of a possible dream, which is the collective construction of the curriculum as our praxis' basis. By observing and investigating documents from the partner school and Minas Gerais' Secretariat of Education (SEE-MG), about the curricular project of schools taking part in the Full-Time Education Program (PROETI), the group involved in the research carried out interviews and epistemological circles, with the objective of constructing a democratic curricular proposal. About its Freire foundations, the research is qualitative and follows the research-action methodology, given that the purpose is to organize an intervention with educators and learners at the to-dos in the full-time period.

- Doutor em

Educação Pelo

PUC SP, Docente

do PPGE PUC

Minas.E-mail

Keywords: Full-time education; Curriculum; Paulo Freire. 


\section{INTRODUÇÃO}

O tempo integral na escola tem sido uma das soluções apresentadas para a melhoria da qualidade da educação escolarizada que passou a ter grande espaço no Brasil contemporâneo. Com isso, o projeto de Escola em Tempo Integral tem se colocado como valiosa estrutura que possibilitaria o redimensionamento do tempo e do espaço escolar ao oferecer maior tempo de permanência aos estudantes, favorecendo, assim, o processo de ensino-aprendizagem e o desenvolvimento de uma educação de maior qualidade. Existe grande esperança da sociedade brasileira na realização do salto de qualidade que a educação pode dar por meio da oferta de uma Escola em Tempo Integral.

A proposta desse tipo de escola foi tema de campanha dos candidatos mais expostos pela mídia na última eleição presidencial ocorrida em 2014, sendo compreendida como uma das grandes possibilidades de desenvolvimento da sociedade brasileira.

É correto afirmar que, apesar da temática ocupar um lugar privilegiado na atualidade, a Educação Integral tem sido objeto de projetos há um bom tempo na educação brasileira. Como explica a Secretaria de Educação Continuada, Alfabetização e Diversidade do Ministério da Educação (SECAD):

A Educação Integral tem sido um ideal presente na legislação educacional brasileira e nas formulações de nossos mais brilhantes educadores. Iniciativas diversas, em diferentes momentos da vida pública do país, levaram esse ideal para perto das escolas, implantando propostas e modelos de grande riqueza, mas ainda pontuais e esporádicos (BRASIL, 2009, p. 05).

Faz-se necessário esclarecer que, nesta pesquisa, entendemos a Educação Integral como uma educação que promova o desenvolvimento e a formação humana em suas dimensões, a saber: intelectual, cultural, estética, política, física, emotiva, entre outras, o que potencializam um conhecimento transformador tanto dos sujeitos quanto da sociedade.

Assim, um importante desafio que se coloca frente à ampliação da jornada escolar é o desenvolvimento de uma proposta curricular para a Educação Integral. A permanência prolongada na escola só faz sentido como forma de privilegiar uma educação de qualidade que tenha no seu projeto de seleção e distribuição do conhecimento seu principal fundamento. A qualidade aqui colocada diz respeito à promoção de um ambiente educativo para além do tempo e do conhecimento 
especializado, ou seja, um ambiente que proporcione uma educação integral transformadora de sujeitos nas várias dimensões.

Para fundamentar a construção desse currículo, buscamos no pensamento freireano o aporte epistemológico e metodológico necessário para o desenvolvimento do um ambiente dialógico e horizontalizado, que permite uma visão integrada sobre o papel da escola a partir de círculos de cultura em que educadores(as) e educandos(as) se tornam protagonistas na construção do projeto curricular.

O lócus para desenvolvimento da pesquisa é uma escola estadual de Belo Horizonte (MG), onde o Programa Mais Educação é adotado e oferece vagas no PROETI para alunos(as) do Ensino Fundamental.

\section{Escolhas metodológicas}

As escolhas metodológicas são cruciais para o processo de pesquisa, uma vez que definem a aproximação dos pesquisadores ao objeto a ser estudado e condicionarão a subsequente intervenção planejada a ser implementada e, finalmente, revisada. Para construir um currículo crítico, fundamentado em algo concreto, tendo como alicerce a compreensão da realidade como forma de possibilitar sua transformação, deve-se objetivar a autonomia e a transformação do educando(a). Por essa razão, a pesquisa-ação é a estratégia metodológica selecionada como opção qualitativa. Desejamos promover o conhecimento de uma realidade (a proposta curricular atual) para, em seguida, transformá-la, por meio de uma ação que projetamos coletiva. Temos como norteadores desta busca, três aspectos: a investigação, a ação e a participação. Essas três particularidades indicam que o caminho metodológico a ser seguido é a pesquisa-ação, por ser uma forma de “investigação colaborativa e coletiva auto-reflexiva conduzida por participantes a fim de resolver problemas práticos e melhorar a qualidade de algo em qualquer cenário social” (MCKERNAN, 2009, p.143).

Michel Thiollent (2011) traz uma definição mais completa:

A pesquisa-ação é um tipo de pesquisa social com base empírica que é concebida e realizada em estreita associação com uma ação ou com a resolução de um problema coletivo e no qual os pesquisadores e os participantes representativos da situação ou do problema estão envolvidos de modo cooperativo ou participativo (THIOLLENT, 2011, p. 20). 
Como a pesquisa-ação vai além do simples levantamento de dados, ela é utilizada quando se deseja que os sujeitos implicados tenham algo a dizer e a fazer (THIOLLENT, 2011). Esse foi um ponto central nesta escolha, pois aspiramos que educadores(as) e educandos(as) da escola pesquisada (considerados por nós como sujeitos pedagógicos) não sejam simples alvos de nossa análise e exposição, "mas sujeitos e lugares de análise e enunciação" (ROMÃO et al, [19-- ], p.4).

A pesquisa-ação pressupõe interação e algum tipo de cooperação para adquirir caráter participativo, Thiollent (2002) acrescenta que, ao criar o espaço de interlocução para a resolução de problemas, os atores envolvidos na pesquisa-ação participam com saberes diferenciados na sua resolução, desse modo, construindo conhecimento para todos.

\begin{abstract}
Uma pesquisa-ação para que seja participativa, supõe que as pessoas estejam em condições e capacitadas. Para que a participação seja efetiva é necessário resolver algumas questões: Primeira é de criar espaços de participação. É óbvio, não se pode participar se não se tem onde participar. A pesquisa-ação como metodologia de pesquisa e de ação cria espaços onde as pessoas participam do projeto de atuação organicamente estabelecido. Segundo é de proporcionar as pessoas, os instrumentos e a capacitação necessária para saber como participar. Não se trata do "direito à participar", mas da capacidade para poder participar efetivamente (BALDISSERA, 2001, p.10).
\end{abstract}

Oliveira e Oliveira (1983) asseveram que a finalidade da pesquisa-ação é favorecer a aquisição de um conhecimento e de uma consciência crítica. Tem-se, assim, como objetivo na pesquisa-ação estabelecer uma relação entre o conhecimento e ação, entre pesquisadores e sujeitos implicados na situação investigada e desses com a realidade. Michel Thiollent (2011) descreve ser necessário uma extensa e explícita interação entre os pesquisadores e envolvidos na pesquisa e que esta não se limita a uma forma de ação (risco de ativismo), mas pretenda aumentar o conhecimento dos pesquisadores e/ou nível de consciência das pessoas e grupos que participarem do processo, bem como contribuir para a discussão ou fazer avançar o debate acerca das questões abordadas.

“A pesquisa-ação não é constituída apenas pela ação ou pela participação. Com ela é necessário produzir conhecimentos, adquirir experiência, contribuir para a discussão ou fazer avançar o debate acerca das questões abordadas" (THIOLLENT, 2011, p.29).

De acordo com Thiollent (2011), a pesquisa-ação é uma estratégia que deve agregar vários métodos e técnicas da pesquisa social, assim, os instrumentos da 
pesquisa aqui empreendida têm como base os três momentos do Método Paulo Freire para criação dos instrumentos e técnicas da pesquisa que se mesclarão com os três momentos da pesquisa-ação defendidos por Pinto (PINTO apud BALDISSERA, 2001).

A pesquisa-ação é uma estratégia metodológica que deve ter no diálogo sua base. É a partir de uma perspectiva dialógica que Paulo Freire, além de seus fundamentos epistemológicos, participa, também, como fundamento para uma metodologia de pesquisa-ação e de construção curricular, uma vez que sua proposta de currículo parte do estudo da realidade por meio do diálogo entre homens e mulheres mediados pelo mundo. E é por meio de círculos epistemológicos que pretendemos desenvolver o diálogo entre pesquisadores e pesquisandos. Nesse procedimento, buscamos o surgimento de temas geradores, retirados da problematização da prática de vida dos educandos(as) e educadores(as).

Os conteúdos de ensino são resultados de uma metodologia dialógica. Cada sujeito e grupo envolvido na ação pedagógica dispõem em si, ainda que de forma embrionária, dos conteúdos necessários dos quais se parte.

Para melhor compreensão do desenvolvimento da pesquisa e suas conclusões, a opção neste artigo é apresentar os momentos da pesquisa que culminaram no Círculo de Cultura com os educandos(as).

A opção qualitativa, de caráter descritivo-interpretativo, traz a necessidade da humildade epistemológica e do papel desenvolvido pelos pesquisadores, uma vez que os dados coletados passam pelas subjetividades destes e são, a partir dessas subjetividades, expostos. Por isso, as observações e entrevistas são categorizadas por meio das inferências discutidas pelo grupo de pesquisa com base nos dados coletados.

\section{Momentos da pesquisa e suas inferências}

A inserção dos pesquisadores no campo se constitui em momento de estranhamento e aproximação da realidade a ser desvendada. De acordo com Pinto (PINTO apud BALDISSERA, 2001), o objetivo desse momento é criar uma compreensão do grupo com o qual trabalharemos e tentaremos alcançar a percepção que este tem de si e da problemática que se pretende obter.

Nesse momento, buscamos descobrir o campo de pesquisa e os interessados em participar do processo e suas expectativas, para estabelecer um primeiro 
levantamento. Partimos de uma pesquisa sobre a escola, seu contexto e a história da comunidade bairro Cardoso, por meio de registros existentes na própria instituição e na Prefeitura Municipal - Regional Barreiro. Faremos, também, a análise dos documentos oficiais da escola (Projeto Político Pedagógico e o Projeto Estratégico Escola em Tempo Integral).

Desde o início da pesquisa, ficaram evidentes os anseios de educadores e direção da escola sobre o que-fazer em uma Educação em Tempo Integral. Questão que já exteriorizava uma preocupação curricular dentro da acepção trazida pela Professora Ana Saul no Dicionário Paulo Freire: “Currículo é, na acepção freireana, a política, a teoria e a prática do que-fazer na educação, no espaço escolar, e nas ações que acontecem fora desse espaço, numa perspectiva crítico-tranformadora" (SAUL, 2008, p. 120).

Importante ressaltar que a preocupação curricular se apresentou nas falas iniciais desprovidas de qualquer preocupação crítico-transformadora, sendo evidente a busca na melhoria de uma qualidade estabelecida pelo Ideb $^{1}$ e pelo ENEM ${ }^{2}$.

Esse momento inicial foi importante para análise do projeto curricular proposto pela Secretaria Estadual de Educação e para compreensão das interpretações da diretoria da escola, dos educadores(as), dos pais e dos alunos sobre o tempo integral. Com isso ficou claro que as avaliações externas são resultados do trabalho educativo e que o processo ensino-aprendizagem deve buscar uma formação integral, sendo que a formação intelectual não pode ser desprezada.

Assim, as entrevistas e observações possibilitaram algumas inferências sobre o papel da Escola em Tempo Integral nessa comunidade escolar.

$1^{\text {a }}$. Inferência: "é melhor estar na escola do que na rua." (Será?)

O ditado popular teve sua premissa abalada logo no início da pesquisa dada a baixa procura pelo período integral. Situada em um populoso bairro, cujos moradores são majoritariamente pertencentes às classes populares, a escola teve aberta 50 vagas para o tempo integral, mas teve dificuldades para conseguir 25 matrículas. Já a frequência durante o ano que se desenvolveu a pesquisa girou em torno de $50 \%$ (cinquenta por cento).

A partir dos educadores, que trabalharam no tempo integral, especificamente a professora de Português, pudemos compreender um dos problemas da própria proposta e premissas do Programa Educação em Tempo Integral: “Alguns pais não
"O Î́ndice de Desenvolvimento da Educação Básica (Ideb) foi criado pelo Inep em 2007 e representa a iniciativa pioneira de reunir em um só indicador dois conceitos igualmente importantes para a qualidade da educação: fluxo escolar e médias de desempenho nas avaliações. Ele agrega ao enfoque pedagógico dos resultados das avaliações em larga escala do Inep a possibilidade de resultados sintéticos, facilmente assimiláveis, e que permitem traçar metas de qualidade educacional para os sistemas. $\mathrm{O}$ indicador é calculado a partir dos dados sobre aprovação escolar, obtidos no Censo Escolar, e médias de desempenho nas avaliações do Inep, o Saeb - para as unidades da federação e para o país, e a Prova Brasil - para os municípios." (INSTITUTO NACIONAL

DE ESTUDOS E PESQUISAS EDUCACIONAIS ANÍSIO TEIXEIRA, 2011).

"Criado em 1998, o Exame Nacional do Ensino Médio (Enem) tem o objetivo de avaliar o desempenho do estudante ao fim da escolaridade básica. Podem participar do exame alunos que estão concluindo ou que já concluíram o ensino médio em anos anteriores.O Enem é utilizado como critério de seleção para os estudantes que pretendem concorrer a uma bolsa no Programa Universidade para Todos (ProUni). Além disso, cerca de 500 universidades já usam o resultado do exame como critério de seleção para o ingresso no ensino superior, seja complementando ou substituindo o vestibular" (BRASIL, c2015). 
querem misturar seus filhos com crianças-projeto, porque entendem que só crianças problemáticas ficam no tempo integral."

Realmente, o desenvolvimento de um projeto que tenta privilegiar crianças em situação de risco possibilita uma compreensão, segundo a qual o espaço do período integral se constitui em ambiente para a chamada "criança-problema".

Para ficar clara a questão, vejamos o ofício da Secretaria Estadual de Educação de Minas Gerais em que se determina o público prioritário para o Projeto Educação em Tempo Integral (PROETI):

O Projeto Educação em Tempo Integral deve ser desenvolvido, prioritariamente, com alunos em situação de vulnerabilidade:

- em distorção de idade-ano;

- onde houver necessidade de correção de fluxo (redução da evasão e/ou repetência);

- beneficiários do Programa Bolsa Família;

- abuso, violência e trabalho infantil;

- com baixo rendimento escolar;

- em progressão continuada (alunos do $6^{\circ}$. ao $9^{\circ}$. ano) (MINAS GERAIS , 2014).

É compreensível que o início da ampliação do tempo na escola seja prioritariamente para as crianças e jovens que necessitam da atenção do serviço educacional público. Mas devemos discutir a razão da não-universalização do tempo integral, pois gera distorções graves sobre o papel da escola e da educação escolarizada em nossa sociedade.

A partir dos fatos observados, podemos interpretar que os gestores, educadores(as) e pesquisadores, dedicados ao campo da educação escolarizada, têm um grande desafio a enfrentar, pois mais tempo na escola deve obrigatoriamente se traduzir em uma maior qualidade. A escola tem uma responsabilidade social que é a formação das crianças e não pode ser concebida como depósito de crianças.

Apesar de este não ser o foco de nossa pesquisa, temos que é necessária a digressão para compreensão do desafio que é a ampliação da jornada escolar, pois como política pública educacional, a Educação em Tempo Integral deve estar comprometida com a formação integral dos educandos(as) e não como forma de “depositar” crianças em um ambiente supostamente seguro.

Daí a necessidade de reflexão sobre este projeto que não pode ficar restrito ao princípio de que mais tempo na escola basta. Precisamos de mais educação e o papel do projeto curricular é fundamental para tanto. 
2a . Inferência: "Da proposta à ação: o currículo no contraturno"

Infelizmente, a realidade das escolas, tanto públicas como privadas, tem se desenhado a partir da fragmentação de turnos, ou seja, turno e contraturno seriam a possibilidade de prolongamento do tempo na escola. Obviamente, não se nega a dificuldade de uma educação integral a partir desta fragmentação, mas também não se pode ignorar essa realidade.

É na perspectiva dessa fragmentação que a proposta curricular do PROETI (MINAS GERAIS, 2014) traz a previsão de áreas do conhecimento para o contraturno, tais como aulas de Linguagem, Matemática, Educação Física, Arte, Formação de Hábitos. Prevendo disciplinas para o desenvolvimento dessas áreas com sua carga horária.

Quadro 1 - Matriz Curricular para o ano de 2014

\begin{tabular}{|l|l|c|}
\hline \multicolumn{1}{|c|}{ Componente Curricular } & \multicolumn{1}{|c|}{$\begin{array}{c}\text { Áreas Curriculares } \\
\text { Disciplinares }\end{array}$} & Carga Horária Semanal \\
\hline \multirow{4}{*}{ Linguagem } & Alfabetização e Letramento & 05 \\
\cline { 2 - 3 } & Leitura & 02 \\
\cline { 2 - 3 } & Redação & 01 \\
\hline \multirow{2}{*}{ Linguagem Matemática } & Experiências Matemáticas & 03 \\
\cline { 2 - 3 } & Jogos e Desafios Matemáticos & 03 \\
\cline { 2 - 3 } & Estudo Monitorado & 04 \\
\hline Educação Física & Jogos e Atividades Esportivas & 02 \\
\hline \multirow{2}{*}{ Arte } & Arte e Artesanato & 01 \\
\cline { 2 - 3 } & Artes Visuais & 01 \\
\hline Formação de Hábitos & Hábitos e Higiene & 05 \\
\cline { 2 - 3 } & Higiene Corporal & 01 \\
\cline { 2 - 3 } & Educação para o Trânsito & 01 \\
\cline { 2 - 3 } & Orientação Sexual & 01 \\
\hline Subtotal & & 30 aulas \\
\hline
\end{tabular}

Fonte: (MINAS GERAIS, 2014)

A proposta curricular para jornada estendida tem também outra orientação mais restritiva da Secretaria de Estado da Educação de Minas Gerais (SEED/MG) por meio de um documento intitulado "Programa Estruturador Educação para Crescer: Projeto Estratégico 'Educação em Tempo Integral' - Orientações para Implantação do Projeto/Operacionalização". Nessa orientação são trazidas explicitamente somente três áreas do conhecimento escolar a serem desenvolvidas no PROETI, quais sejam, Português, Matemática e Educação Física. Na escola pesquisada são essas as disciplinas do chamado "contraturno", também conhecido por eles como "tempo integral" ou "projeto", sendo que, ao indagar a Diretora da escola sobre os outros temas previstos no Plano Curricular, fomos informados de que 
a Formação de Hábitos e Arte são desenvolvidas de forma transversal em todas as disciplinas.

Na observação realizada durante um ano, pelo menos uma vez por semana, não se identificou nenhuma atividade ligada aos temas, exceto um filme exibido na sala de multimeios que ocupou algumas aulas de Matemática, sendo que, ao seu fim, não houve nenhum comentário do professor.

Nas observações realizadas ficou evidente a intenção dos professores de Matemática e Português destinarem prioritariamente a sua carga horária no contraturno exclusivamente ao reforço do conteúdo trabalhado no tempo regular.

Essa prática se revelou um grande desafio em uma turma que se caracteriza pela heterogeneidade, uma vez que os alunos matriculados são de idades e anos diferentes.

Já as aulas de Educação Física se centraram no lazer com jogos de Tênis de Mesa, Xadrez e Damas.

Como vemos, a concepção de currículo como aquilo que deve ser ensinado na escola passa longe da realidade do cotidiano escolar, sendo ingênua a premissa que a verticalização da proposta curricular é sinônimo de qualidade, pois ignora o quefazer da escola e o currículo oculto.

Desse modo, essa questão enfatiza a importância de compreender o currículo como o que é feito na escola e o papel do professor neste fazer.

\section{3a . Inferência: "Círculo epistemológico e a Cultura do Silêncio"}

A primeira tentativa de construção de um Círculo de Cultura, para buscarmos as falas significativas, foi em um encontro com os três professores do contraturno, três pesquisadores e outros dois professores(as) que dão apoio à pesquisa no interior da escola.

Buscamos um momento que interrompesse a postura distante de pesquisador em prol de um momento de partilha do conhecimento e de projetos, no intuito de desenvolver um diálogo em que a escuta e a palavra fossem valorizados.

Neste momento planejamos selecionar as falas significativas $^{3}$, sendo momento fundamental para nossa proposta de pesquisa, pois a expectativa era estabelecer uma relação dos temas de uso corrente nas vozes dos educadorespesquisandos. A pretensão era identificar alguns temas geradores reveladores das 
contradições sociais e pedagógicas, correspondentes à representação da escola em tempo integral.

Como Romão (et al., [19-- ]) explicam, é necessário discutir nossa incompletude, inconclusão e inacabamento como forma de se conscientizar da especificidade ontológica humana.

Todos os seres - pelo menos os que conhecemos até o momento - são incompletos, inconclusos e inacabados. São incompletos, porque necessitam dos outros; são inconclusos, porque estão em evolução, e são inacabados, porque são imperfeitos. O ser humano se distingue dos demais, apresentando uma especificidade ontológica, por ter consciências destes "limites", por saber-se incompleto, inconcluso e inacabado. E, por causa desta singularidade, acaba por viver uma tensão permanente entre a insatisfação de ser o que é (incompleto, inconcluso e inacabado) e a aspiração de "ser mais" (completo, concluído e acabado) (ROMÃO et al, [19-- ], p. 5).

A partir da compreensão de inacabamento, incompletude e inconclusão, foi exposto no círculo que tanto o projeto de escola como a proposta curricular revelamse imperfeitos e necessitam do diálogo para sua constante evolução, tendo os educadores um papel muito importante nessa aspiração de melhoria. A questão de uma formação integral fez parte do debate e essa é um novo desafio para a sociedade brasileira.

Assim foi colocada a questão para os educadores:

\begin{abstract}
Essa escola em tempo integral, como vocês sabem, é algo muito novo, e é uma caminhada que está no início. Com todos os problemas que temos na escola, estender o tempo dessas crianças dentro da escola, dentro do espaço que muitas vezes não está preparado para recebê-las, é um grande desafio. Desafio para professores, crianças e pais que não estão acostumados com esse novo sistema de educação, não é?! Então, a gente queria saber como vocês veem esta proposta - o funcionamento do contraturno -, qual é a importância e o problema, pois o tempo integral não é só solução, ele traz, também, alguns problemas pra escola?
\end{abstract}

Dessa forma, os participantes puderam verbalizar suas angústias e frustrações sobre a ampliação da jornada escolar e revelaram que o problema central reside na aprendizagem, ou seja, os problemas seriam somente os educandos(as). Este problema deriva, segundo os professores, do desinteresse dos educandos(as) e da obrigatoriedade imposta pelos pais da frequência do contraturno.

Além disso, ficou patente nas falas dos professores(as), a compreensão de que um importante papel social da ampliação da jornada é receber as crianças que não têm onde ficar, ou seja, surge a questão que o espaço escolar serve de "depósito".
SILVA (2004) define "falas significativas" como as falas dos diferentes segmentos escolares que trazem a denúncia de algum conflito ou contradição vivenciados pela comunidade local e que expressa uma determinada concepção, uma representação do real. 
Desse modo, segundo o professor de Matemática, "a mentalidade de muitos do projeto, acho que de uns setenta por cento ou mais, acho que veio porque, aí entra o lado social, veio porque a mãe quer que ele fique". E completa, "ele (o tempo integral) vale a pena, não é só a questão de aprendizagem, é mais pelo social [...]”

A visão dos professores sobre o tempo integral e a função da escola evidenciou uma dupla função do contraturno: promover o desenvolvimento intelectual com o ensino das disciplinas eleitas e um ambiente seguro de permanência dos educandos(as).

Como o objetivo principal do círculo epistemológico era a busca por temas a serem desenvolvidos no tempo integral, foi perguntado, por uma das pesquisadoras, quais seriam as atividades ou temas que poderiam despertar um maior interesse dos educandos e educandas e, ainda, como poderíamos vislumbrar uma proposta curricular para o próximo ano diante das experiências vividas em 2014.

A professora de Português apontou que eles só se interessam por informática e, assim, ela faz uma barganha ao prometer que, se eles realizarem as tarefas da disciplina de Português, poderão usar o laboratório.

É tem que ter troca para esses meninos. A última aula que eu fui com eles para a informática. Eu disse: "não vai ter informática não, eu sou paga para ser professora de Português, nós vamos fazer uma atividadezinha legal e, se não ficar bacana, nós não vamos não.

Nesse caso, os professores de Matemática e Educação Física concordaram com a utilização deste tipo de chantagem para realização de atividades.

Foram indicadas, com grande ênfase, atividades fora da escola, mas, ao tentarmos vincular essas atividades ao conhecimento escolarizado, não houve nenhuma conexão. Essa desconexão entre o conhecimento escolar e atividades realizadas fora da escola ficou evidente em uma das poucas saídas da turma da Escola em Tempo Integral, quando houve a viagem para Ouro Preto. As crianças foram com um professor e uma pesquisadora, fizeram a visita, tiveram explicações sobre a cidade, mas esse espaço e tempo não se vincularam à formação promovida pelos professores que lecionam no contraturno.

A questão dos temas foi reiteradamente colocada, mas não emergiu de nosso círculo nenhuma temática das falas. Tivemos somente questões referentes à estratégias pedagógicas e à responsabilização dos educandos e educandas pelos problemas de aprendizagem e infrequência no contraturno. 
Apesar da frustração da equipe de pesquisadores, a realização de um evento em que podemos compreender as possibilidades e os condicionamentos dos educadores da escola foi de fundamental importância no prosseguimento da pesquisa. Ficou mais evidente a dificuldade do professor em compreender seu papel na coletiva de uma proposta curricular. O que emergiu deste momento foi a demanda destes educadores em receber da pesquisa uma proposta de temas, quando a pretensão sempre foi uma construção coletiva.

Freire (2005), na obra Pedagogia do Oprimido, traz algumas indicações que permitem compreender a rejeição ao novo e ao transformador trazida nesse Círculo. O autor explica que a Educação Bancária condiciona os sujeitos a uma "cultura do silêncio" que traz a desconfiança do protagonismo do povo na transformação. "Desconfiança que o povo seja capaz de pensar certo. De querer. De saber" (FREIRE, 2005, p. 53).

A "cultura do silêncio" impossibilita homens e mulheres de dizerem sua Palavra, apresentarem sua Leitura de Mundo como sujeitos de ação e reflexão, ou seja, interdita a participação popular e uma educação transformadora.

Necessário reconhecer, neste contexto, que "a leitura do mundo e da palavra é, em Freire, direito subjetivo, pois, o dominando signos e sentidos, nos humanizamos, acessando mediações de poder e cidadania" (PASSOS, 2008, p. 240).

Na obra Ação cultura para liberdade e outros escritos, de Paulo Freire, a "cultura do silêncio" é indicada como uma estratégia para manter o povo no estado de dependência e em nada contribui para a superação da percepção fatalista em face de suas situações-limites (FREIRE, 2002).

As situações-limites foram expostas pelos pesquisadores e educadores com muitos detalhes. No entanto, assumir-se protagonista da mudança e sujeito da busca do inédito-viável se revelou, nesse momento, um enorme desafio.

\footnotetext{
Neste caso, os temas se encontram encobertos pelas "situações-limites" que se apresentam aos homens como se fossem determinantes históricas, esmagadoras, em face das quais não se lhes cabe outra alternativa, senão adaptar-se. Desta forma, os homens não chegam a transcender as "situações-limites" e a descobrir ou a divisar, mais além delas e em relação com elas, o "inédito-viável" (FREIRE, 2005, p. 108).
}

A proposta curricular com seus temas geradores pode se constituir nesse inédito-viável que humaniza os sujeitos em prol de um sonho possível e evidencia a busca pela transformação. Mas para isso é preciso ir além do reconhecimento das situações de injustiça, ir além das denúncias, das situações-limites. 
$4^{a}$. Inferência: "Fico com a pureza da resposta das crianças"

O Círculo Epistemológico, que teve a participação de educandos e educandas do PROETI na escola pesquisada, foi realizado um mês após o que aconteceu com os professores(as). Participaram seis pesquisadores, um professor da escola, que trabalha no apoio à pesquisa, quatro alunas e cinco alunos.

Após as apresentações e a ambientação, foram feitas várias críticas sobre o processo de ensino-aprendizagem do tempo integral (contraturno), tendo como foco a monotonia das atividades, a distorção dos conteúdos em relação à diferença de nível de estudos dos educandos e educandas e ao desprezo dos professores em relação aos interesses daqueles.

Após o momento de denúncia, nossa proposta foi buscar o anúncio do porvir com os alunos, explicando a importância deles como sujeitos a dizerem sua Palavra. Sugerimos uma trama conceitual fundada nas relações de temas que deveriam estar presentes na escola. E que, a partir da questão central "ESCOLA", eles indicassem outras atividades significativas. Assim, houve a divisão em três grupos para que, por meio de balões feitos com pincel atômico em cartolinas, pudessem coletivamente realizar a atividade.

A opção feita pela utilização do mapa mental foi com o objetivo de buscar a rejeição da repetição mecânica da informação e privilegiar a apresentação de temas significativos que viabilizam a integração do conhecimento (ZANARDI, 2015).

As crianças se revelaram entusiasmadas com a possibilidade de dizer o que esperam da escola e debateram em grupos as temáticas. Nesse momento foi possível perceber suas concordâncias, suas discordâncias e as contradições que permeiam a vida escola e social.

Após alguns minutos, os grupos terminaram de escrever sua proposta e então veio o momento de partilha dos projetos. Na sequência desse momento tivemos, no Círculo Epistemológico, o espaço para a reflexão sobre a questão geradora do debate: a escola.

O Círculo Epistemológico permite que o pesquisador e o pesquisando reflitam sobre o objeto investigado, mobilizados por uma questão geradora de debate. A partir dela, acontece a enunciação de situações existenciais, carregada de conteúdo emocional, manifesto pelo universo cultural vocabular (ROMÃO et al., [19-- ]. p. 11). 
Ao partilhar suas propostas, as crianças enfatizaram o ceticismo com a esperança da escola em receber a contribuição realizada e explicitaram a razão dos temas selecionados.

Figura 1 -

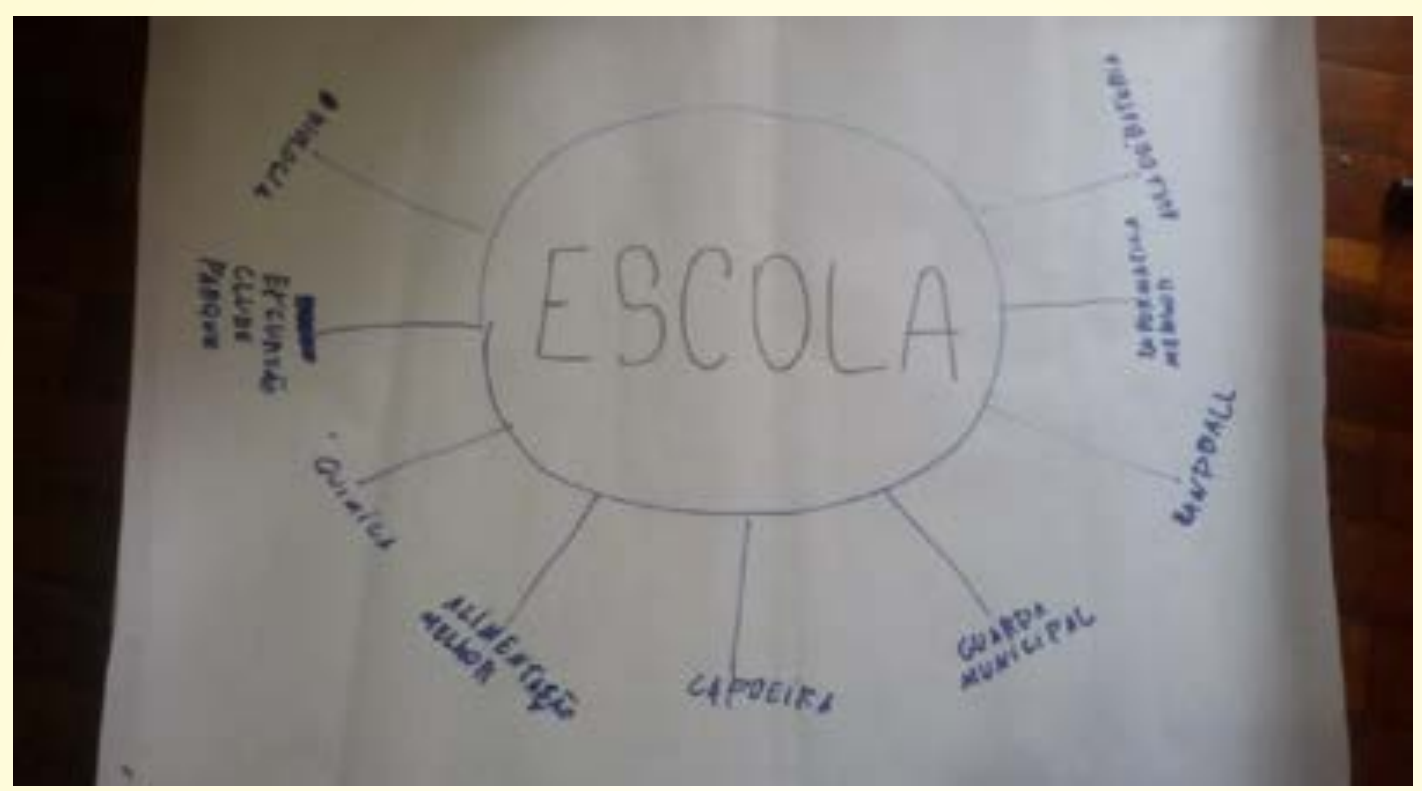

Fonte: Foto do autor

Figura 2

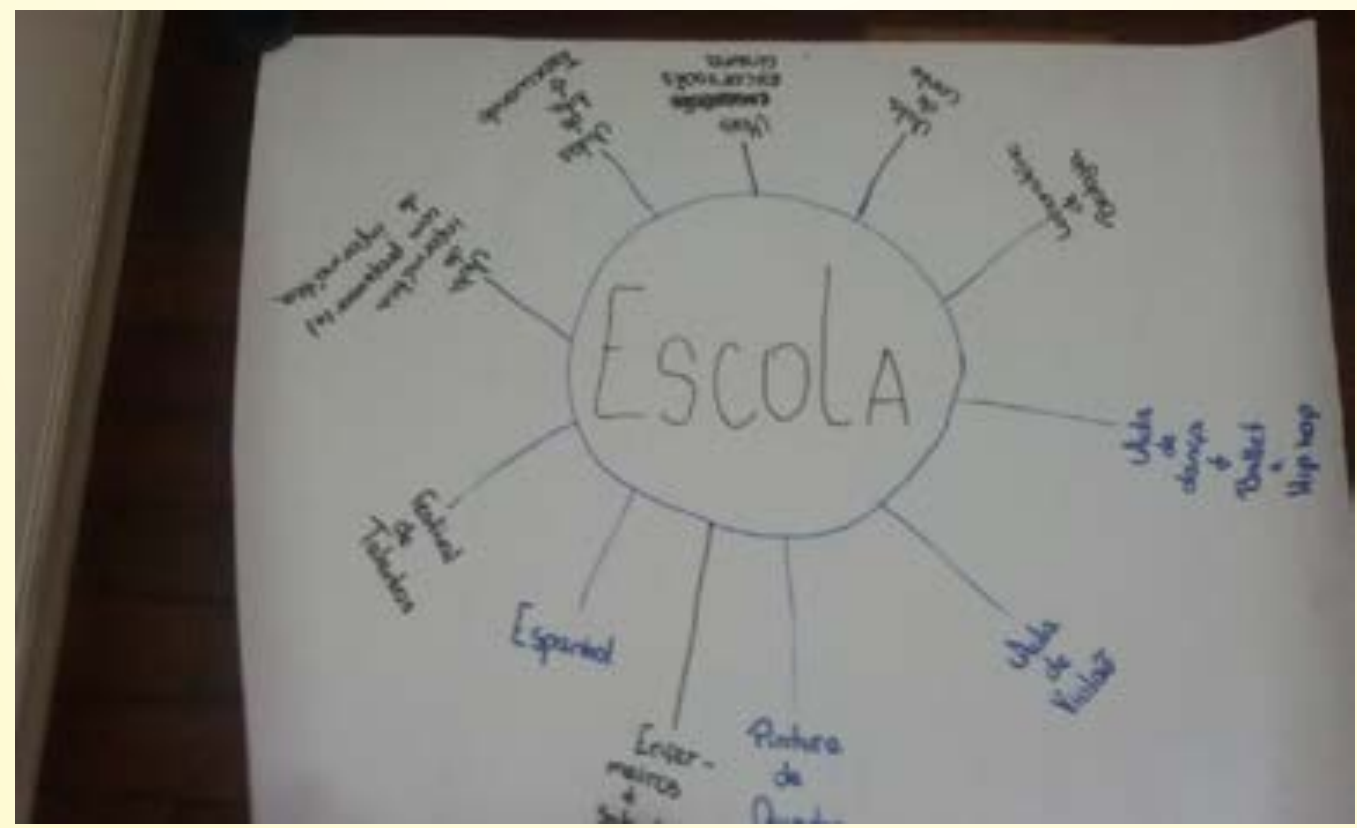

Fonte: Foto do autor 


\section{Figura 3}

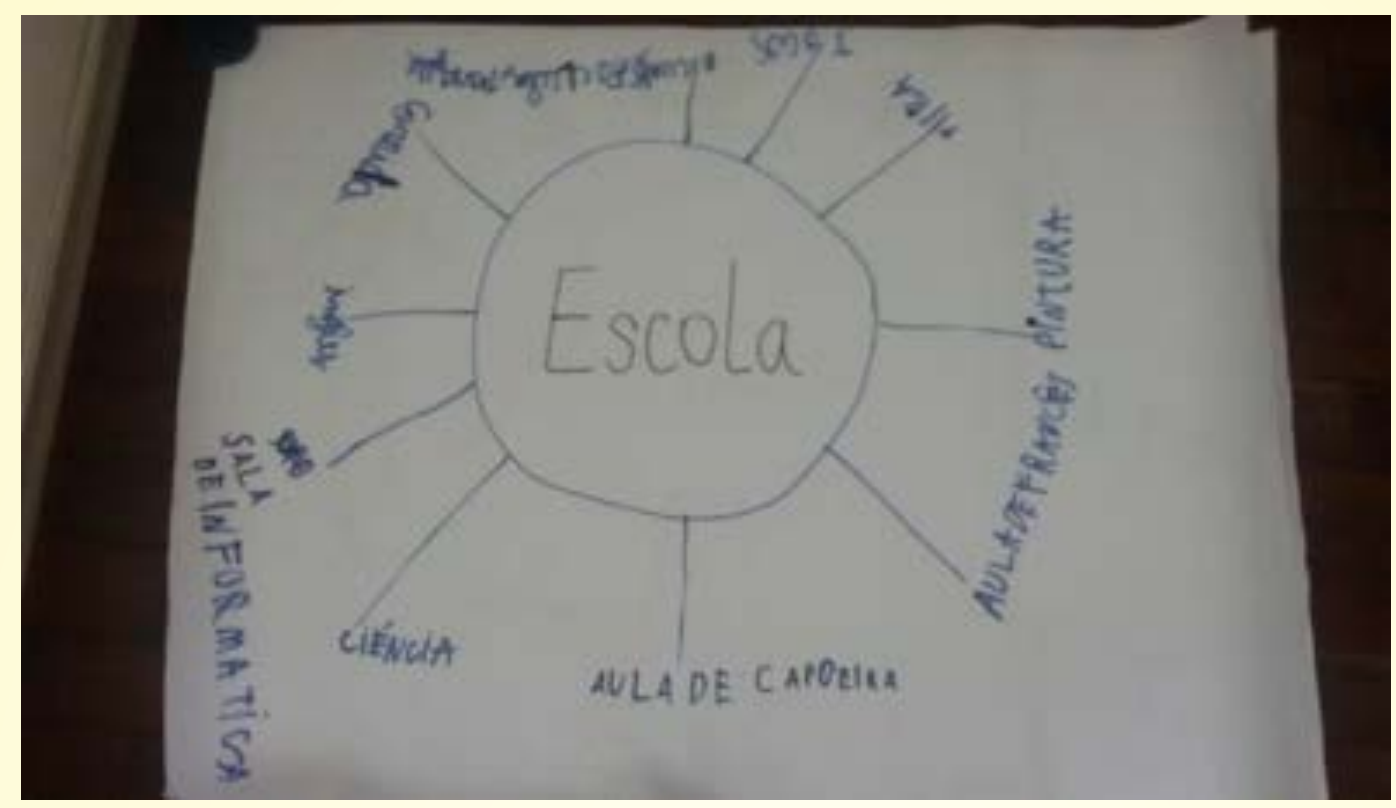

Fonte: Foto do autor

Fomos surpreendidos pela preocupação dos educandos e educandas em relação às disciplinas tradicionais, como Biologia, Química e Física. Os educandos e educandas, que trouxeram esses temas, explicaram que essas áreas despertam o interesse pelas plantas e outros fenômenos da natureza. Apesar das justificativas terem sido superficiais, a apresentação em mais de um grupo das áreas do conhecimento tradicionalmente disponíveis no currículo escolar trouxe a evidência que os próprios educandos e educandas não esperam ficar "depositados" na escola no contraturno e, também, não desejam somente atividades de lazer.

As outras temáticas, que se fizeram presentes com grande intensidade, foram a Linguagem, com idiomas estrangeiros, as Artes, com música, pintura, dança e canto, Esportes e a Informática. Como questões pontuais surgiram as de hábitos alimentares e segurança pública, além da sugestão de atividades extraescolares, como excursões.

No debate ficou evidente como a realidade desses educandos e educandas e seus sonhos convergiam para os temas apontados com uma expectativa de ter o ambiente escolar como um lugar de construção de saberes e realização de utopias.

Em que pese a permanência da fragmentação por áreas e o diálogo com os educandos e educandas proporcionou uma visão de uma curiosidade epistemológica 
que não pode ser desprezada pela escola e deposita nesta a esperança o papel integrador dos conhecimentos em prol de uma formação integral.

Esse Círculo também foi revelador da sintonia da compreensão da proposta curricular constante na Matriz Curricular, já colacionada anteriormente, que a escola em questão nos apresentou. Na matriz estão contidas atividades e áreas do conhecimento que coincidem com aquilo que educandos e educandas esperam ver na escola.

É dessa coincidência curricular que resulta a invocação de Gonzaguinha no título deste tópico, faz-se necessário ressaltar a importância da resposta das crianças que o compositor consagrou em sua música O que é? O que é? (1982). Aprender com a resposta das crianças é fundamental para construção de um projeto curricular dialógico. O protagonismo dos sujeitos privilegia o desenvolvimento de suas dimensões ontológicas, seu "ser mais" e epistemológicas, seu "saber mais", com a valorização dos saberes. Valorizadas de maneira a se estabelecer uma relação horizontalizada e dialógica na seleção do que-fazer na escola.

As Diretrizes Curriculares Nacionais para o Ensino Fundamental trazem esta proposição:

Art. $9^{\circ} \mathrm{O}$ currículo do Ensino Fundamental é entendido, nesta Resolução, como constituído pelas experiências escolares que se desdobram em torno do conhecimento, permeadas pelas relações sociais, buscando articular vivências e saberes dos alunos com os conhecimentos historicamente acumulados e contribuindo para construir as identidades dos estudantes (BRASIL, 2010).

A resposta das crianças traz consigo a proposição do inédito-viável contido nas Diretrizes. Já a compreensão do inédito-viável visibiliza-se na emergência de uma construção curricular humanizante em que os sujeitos assumam seu papel de produtor de saberes, sendo a escola um lugar de alimento da curiosidade. $\mathrm{O}$ currículo, desse modo, é simultaneamente investigação e conhecimento; é a busca e o encontro. O conhecimento e o ensino-aprendizagem frutificam a partir do diálogo entre sujeitos com a articulação entre saberes e vivências. Diálogo que, ao romper a cultura do silêncio, humaniza e possibilita a transformação por meio do processo educativo. 


\section{Considerações finais: um currículo inédito e viável}

Ficou evidente que a Educação Integral ainda se encontra distante do tempo integral da escola pesquisada, as ações dessa estão permeadas por um objetivo de desenvolvimento intelectual, que deixa de lado outras dimensões fundamentais para a realização da desejada formação humana integral.

O desafio da pesquisa, que ainda está em sua fase final em que se pretende experienciar os temas geradores, é buscar a construção de um projeto curricular para Escola em Tempo Integral sob bases dialógicas e, portanto, desenvolvido com os sujeitos da escola. Nosso entendimento é que com o diálogo emergem saberes e projetos de formação que apontam em várias direções, permitindo a superação da visão unilateral de escola, na qual a única questão importante é o desenvolvimento intelectual.

Após um longo período de observação, entrevistas e debates em Círculos Epistemológicos, é possível revelar nossa esperança em um currículo gestado no interior da escola e que tenha educadores e educandos(as) como protagonistas. Um currículo construído a partir da Leitura de Mundo e da pronúncia da Palavra.

Fica clara a concepção curricular que as Diretrizes Curriculares Nacional para o Ensino Fundamental, ao dispor que o currículo é o conjunto de práticas que articulam os saberes, trazem para o centro principiológico da educação o diálogo entre os sujeitos da escola, abandonando a postura vertical e autoritária de um currículo desenvolvido por especialista. O currículo deve, então, desenvolver-se pelo diálogo entre educadores(as) e educandos(as).

Em que pese a "cultura do silêncio" que se estabeleceu no diálogo com os educadores(as), a fé na construção de um currículo na democracia e não para a democracia se desvelou no Círculo Epistemológico realizado com meninos e meninas que compreendem a importância da educação escolarizada e percebem o espaço e tempo da jornada ampliada como ambiente que deve necessariamente promover o seu ser mais e sua busca em saber mais. Um currículo calcado na participação que não protela essa e o componente democrático - fundamental para escola - para um futuro.

No que diz respeito à proposta curricular foi possível inferir que o inédito não está nos conhecimentos tematizados pelos educandos(as), e sim na horizontalização e dialogicidade na construção de um currículo que viabilize a emergência da Palavra daqueles que são subalternizados nas suas relações com o currículo. Já a viabilidade 
é evidente pela própria convergência dos temas e falas significativas dos educandos(as) com a Matriz Curricular oficial. Os temas que emergiram do Círculo realizado com os educandos(as) representam o grito por uma educação integral que precisamos escutar, não podendo o currículo e seus especialistas manterem à margem do que-fazer na escola os seus sujeitos. É necessário empoderar esses sujeitos por meio do diálogo e da educação na democracia.

A nossa pesquisa não terminou, assim como a construção do currículo inédito-viável não se conclui, pois é fundamental percebermos o papel da educação escolarizada e de uma educação integral como instrumento de humanização.

\section{REFERÊNCIAS}

BALDISSERA, Adelina. Pesquisa-ação: uma metodologia do 'conhecer' e do 'agir'. Revista Sociedade em Debate, Pelotas, v. 7, n. 2, p. 5-25, ago. 2001.

BRASIL. Ministério da Educação. Educação integral/educação integrada e(m) tempo integral: concepções e práticas na educação brasileira: mapeamento das experiências de jornada escolar ampliada no Brasil. Brasília: MEC, 2009.

BRASIL. Ministério da Educação Resolução n. 7, de 14 de dezembro de 2010. Diretrizes curriculares nacionais para o ensino fundamental. Brasília: MEC, 2010.

BRASIL. Ministério da Educação. ENEM : apresentação. Brasília: MEC, c2015 Disponível em: < http://portal.mec.gov.br/index.php?option=com_content\&view=article\&id=183\&Ite mid $=310>$. Acesso em: 10 set. 2015.

FREIRE, Paulo; SHOR, Ira. Medo e ousadia: o cotidiano do professor. 3. ed. Rio de Janeiro, Paz e Terra, 1986.

FREIRE, Paulo. Ação cultural para liberdade e outros escritos. 10. ed. Rio de Janeiro: Paz e Terra, 2002.

FREIRE, Paulo. Pedagogia do oprimido. 48. ed. Rio de Janeiro: Paz e Terra, 2005.

INSTITUTO NACIONAL DE ESTUDOS E PESQUISAS EDUCACIONAIS ANÍSIO TEIXEIRA. O que é IDEB?. Brasília: INEP, 2011 Disponível em: $<$ http://portal.inep.gov.br/web/portal-ideb/o-que-e-o-ideb>. Acesso em: 10 set. 2015.

MCKERNAN, J. Currículo e imaginação: teorias do processo, pedagogia e pesquisa-ação. Porto Alegre: ARTMED, 2009.

MINAS GERAIS. Secretaria de Estado da Educação de Minas Gerais. Plano Curricular: ensino fundamental : Projeto Escola de Tempo Integral. Belo Horizonte: 2014. Mimeografado. 
MINAS GERAIS. Secretaria de Estado da Educação de Minas Gerais. Ofício Circular Dire B n. 03/2014. Belo Horizonte: 2014a. Mimeografado.

OLIVEIRA, Rosiska Darcy de; OLIVEIRA, Miguel Darcy de. Pesquisa social e ação educativa: conhecer a realidade para poder transformá-la. In: BRANDÃO, Carlos Rodrigues (Org.). Pesquisa participante. 3. ed. São Paulo: Brasiliense, 1983.

PASSOS, Luiz Augusto. Leitura do Mundo. In: STRECK, Danilo R.; REDIN, Euclides; ZITKOSKI, Jaime José. Dicionário Paulo Freire. Belo Horizonte: Autêntica, 2008.

ROMÃO, José Eustáquio et al. Círculo epistemológico: círculo de cultura como metodologia de pesquisa. São Paulo: Universidade Nove de Julho, [19-- ]. Mimeografado.

SAUL, Ana Maria. Currículo. In: STRECK, Danilo R.; REDIN, Euclides; ZITKOSKI, Jaime José. Dicionário Paulo Freire. Belo Horizonte: Autêntica, 2008.

SILVA, Antônio Fernando Gouvêa da. A construção do currículo na perspectiva popular crítica: das falas significativas às práticas contextualizadas. 2004. $405 \mathrm{f}$. Tese (Doutorado) - Programa de Pós-Graduação em Educação, Pontifícia Universidade Católica de São Paulo, São Paulo. 2004.

THIOLLENT, Michel. Construção do conhecimento e metodologia da extensão. In: CONGRESSO BRASILEIRO DE EXTENSÃO UNIVERSITÁRIA, 1., 2002, João Pessoa. Anais... João Pessoa: UFPB, 2002.

THIOLLENT, Michel. Metodologia da pesquisa-ação. 18. ed. São Paulo: Cortez, 2011.

ZANARDI, Teodoro Adriano Costa. Classes multisseriadas, temas geradores e integração curricular: de Petersen a Freire. Revista Cocar, Belém, v. 9, n.17, p. 4354, jan./jul. 2015. 